Dear author,

Please note that changes made in the online proofing system will be added to the article before publication but are not reflected in this PDF.

We also ask that this file not be used for submitting corrections. 


\title{
A comparative study into how pupils can play different roles in co-design activities
}

\author{
Monica Landoni ${ }^{\mathrm{a}, *}$, Elisa Rubegni ${ }^{\mathrm{b}}$, Emma Nicol $^{\mathrm{c}}$ \\ ${ }^{a}$ Faculty of Informatics, Università della Svizzera italiana, USI, Switzerland \\ ${ }^{\mathrm{b}} \mathrm{HCI} /$ Games Computing, College of Science, University of Lincoln, UK \\ Department of Computer and Information Sciences, University of Strathclyde, UK
}

\section{A R T I C L E I N F O}

\section{Article history:}

Received 20 December 2016

Received in revised form 2 March 2018

Accepted 15 April 2018

Available online $\mathrm{xxxx}$

\section{Keywords:}

Design experience

Evaluation

Collaborative design

\begin{abstract}
A B S T R A C T
We explore the roles children play in the design and evaluation of technological tools in a formal educational environment. In order to do so, we describe two separate projects set in a formal educational context: primary schools, with children aged 8-10, in Switzerland (called PADS), and with older students, 11-12, in Scotland (called CHIS). In the first case the teacher and pupils were co-designing a novel application to support the creation of multimedia fairy tales, where in the second students and teachers worked towards the definition of new tools to assist them in searching for information. The tasks were different but comparable in terms of complexity and level of interest expressed by children. Researchers followed a similar approach in order to interact with the stakeholders. We here describe the different attitudes and assumptions of the adults involved. In the Scottish study these encouraged students to make choices, propose solutions and work independently. In the Swiss study these aimed at supporting children use of digital media and artefacts for the creation of a digital fairy tale. Our investigation aims at getting a better understanding of the kind of roles and contributions young users could bring to collaborative design and how to better engage and motivate them.
\end{abstract}

(C) 2018 Published by Elsevier B.V.

\section{Introduction}

There is a rich literature discussing why and describing how involving children in collaborative design is beneficial for all stakeholders. Here we want to explore the many nuances of this involvement and the implications in terms of roles and assumptions made about children's ability to contribute to design, and what form this contribution can take. Specifically, we target scenarios where activities are set directly by teachers in a formal educational environment as part of the school curriculum.

In this pilot study we set out to explore what are the conditions that impact on children's levels of participation in co-design activities, as well as on the roles that children play within the co-design process.

We approach this exploration by collecting and analysing data from two case studies that differ in the main research question but converge on the approach used for involving young users in terms of: types of activity, methods, quality of participation, contribution and overall significance of data gathered. The two case studies ran in different European countries: Scotland and Switzerland. In the Scottish study, students were asked to engage with search related

\section{* Corresponding author}

E-mail addresses: monica.landoni@usi.ch (M. Landoni),ERubegni@lincoln.ac.u (E. Rubegni), Emma.nicol@strath.ac.uk (E. Nicol). activities according to their teachers' instructions. The focus of the project was on gathering a rich corpus of data about how students choose their search strategies and how influenced they are by many factors (including: available technology/resources and familiarity with these, guidance from teachers and peers, complexity of task and overall intrinsic and extrinsic motivations). Thus, it concentrates on a specific aspect of designing with children, that of gathering effective user requirements. Children were observed over a several months" period of time in order to understand their practices and were mainly acting as informants, not only by being involved in interviews and focus groups, but most crucially, by naturally taking control of the assigned task and performing it from beginning to end in a critical fashion.

The Swiss project aimed at exploring the extent to which digital technology can support primary school curriculum enactment and investigated how to introduce it into existing practices. One of the outcomes was the design of a novel application for the creation of multimedia fairy tales in school. We here describe how children were involved in its collaborative design and specifically focus on their role as evaluators.

In both projects the teachers and children had an important role in defining and performing the tasks. By looking at the evidence that emerged from the data of the two projects we explore the different roles that children of similar age played in the co-design 
process. With the understanding of the two projects' diverse aims and purposes, we bring some light to the many factors to be considered by researchers when designing with and for children in a formal educational context.

We start with our literature review describing co-design projects involving children and more specifically those taking place in a formal school context. We will focus on studies defining conditions and principles for ensuring children's participation and engagement. We will use these to describe the two projects and the influence that teachers had on the roles that children played in each of them. From the analysis of the data produced by the projects we will interpret how children's participation and engagement varied according to the way in which teachers instructed them, and finally we will discuss how our findings can help to inform future research.

\section{Literature review}

The role of children and their engagement in the design process has been a key issue in the Children-Computer Interaction (CCI) community. For instance, in 1999 Druin in her seminal work [1] discussed the potential roles of children in the design process following a co-design perspective. Indeed, pupils in co-design are often included as part of the team with adults. The Cooperative Inquiry method defines well the roles that children can play in the different phases of the process [1] in an intergenerational team. Druin originally defined four different roles: user, tester, informant and design partners. However, even if this framework is extremely valid from a theoretical as well as a practical point of view, the boundaries between the roles are blurred [2]. By reflecting on the political value of the design process as a means to empower its actors, Iversen et al. [3] provide an interesting insight into how to make children truly protagonists in the process.

Considering specific projects in the field of writing and reading Summers et al. [4] engaged children as "research partners" for the design of a digital library for kids. They became members of the research team and performed inquiries with their peers in order to gather a consistent understanding of reading activities for children aged 9-14. The engagement of children within the design and the research had definite positive aspects. However, as researchers it is fundamental to take into consideration children's rights and their need to understand how their ideas are used in the process. Indeed, the research community has being paying more and more attention to the ethical aspects of including pupils equally in a design process mainly driven by adults [5]. The value of stakeholders' participation in the process is extremely relevant. This issue is pretty urgent in the formal educational context since this context has specific requirements that must be taken into account by the research team. In this perspective the CARSS model [6] brings all stakeholders' perspectives together by providing a framework for designing and conducting co-design activities in a formal learning environment. CARSS stands for Context, Activities, Roles, Stakeholders and Skills. This model considers children as subjects who are in the process of learning a specific concept as well as learning to use the introduced technology. Where Druin's framework helps to stimulate pupils to co-design and to imagine something that does not exist already, CARSS considers also the pedagogical aspects and other practical issues specific to being in a school. Moreover, Dodero [7] showed how in this context it is critical to find a good balance between stimulating engagement of children and teachers in the co-design process and respecting the school environment and curriculum. Mazzone et al. [8] developed a framework for meaningful design activities based on a study carried out for the design of a music device for children by involving researchers from different disciplines and children from different schools. They reflected on what happened during the design activities and the materials produced therein and aimed to understand how these activities contributed to the design and whether these had involved children in the process in a suitable way. The framework that emerged recommended: involving the teacher/education expert before and during the session to assure the suitability of the tasks for children and to better ensure that activities would be done in a controlled way. They further suggested using props to get children started on an activity and the use of different media to encourage imaginative results. In addition, they recommended varying communication channels and using expressive tools familiar to children such as drawing or storytelling, to make children more at ease when creating and communicating ideas. They advised also that the progress of the activity as well as the end results be recorded in order to aid analysis and enhance understanding of outputs from the activity. Finally, they proposed using experts from different disciplines to analyse the results in order to better assess the relevance of the outputs to the design goal. While in their study they paid some attention to the effects of the procedure and methods used, they argue also that the management of activities in co-design sessions deserves to be studied further. Here is situated the work of Ivari and Kinnula [9] who focused on understanding the genuine participation of children in research projects in school, how the context poses challenges for this, and what this implies for designing with children. Their key recommendation was that researchers must critically examine the goals set for children's participation in design and think carefully about whether these goals are learning-oriented or material outcome-oriented. Ivari and Kinnula [9] suggest taking the research they have conducted further by introducing greater variety e.g., by working with younger children, several teachers and classes, or with even more thoroughly implemented criteria of genuine participation and perhaps to examine gender and cultural aspects of this participation. In particular they discuss using the criteria extracted by Chawla and Heft [10] to assess how genuine participation of children in co-design activities in a school context is:

1. Conditions of Convergence: described how the project should converge in as many aspects as possible to the existing school ethos and curricular activities but also focus on children's genuine interests.

2. Conditions of Entry: is about making sure recruiting and involving children in the project happens via informed consent from them and their families. Entry can also be managed directly by the school for projects that totally overlap with the existing curriculum.

3. Conditions of Social Support: deals with support and encouragement among participants in the co-design activity.

4. Conditions for Competence: where children have a real opportunity to develop new competences, take responsibility for their decisions and see their contribution making a difference, possibly in terms of a physical outcome.

5. Conditions for Reflection: enables children to reflect on the overall experience and understand how decisions were taken and outcomes produced. Children can also take part in evaluation exercises in order to assess how an activity (or even the full project) was run by groups or individual participants.

These conditions were originally devised to support children's participation when planning project phases in community settings and were successfully used by Ivari and Kinnula [9] to describe genuine participation in a number of co-design projects in the school context. Furthermore, these are pretty much in line with the principles of a framework designed by Engle and Conant [11] for promoting productive disciplinary engagement in the same formal context. Productive disciplinary engagement refers explicitly to 
the level of active engagement students feel towards the discipline they are being offered in class.

We aim to show how teachers influenced the roles children played in our two projects and map them to the conditions listed above in order to use data emerging from the two projects to support our observations. But first we will provide a quick description of the two projects.

\section{Children as information seekers (CHIS)}

\subsection{Study aims}

CHIS aimed at understanding how primary school students choose search strategies and how they are influenced in this by factors such as the availability of technology or other information resources, their familiarity with using these resources, instructions given by teachers and comments of their peers, task complexity and overall intrinsic and extrinsic motivations. The aim was to work towards the definition and design of new tools to assist children in searching for information for school and leisure tasks. For the duration of the project a primary school in an inner city area of Scotland was involved. The project lasted 6 months during which time the researchers engaged different stakeholders at different phases of the project and used the already existing school tasks as the basis for the co-design activity required for the definition of new search tools.

\subsection{Curriculum}

The curriculum guidelines developed by teachers in this school stated that children should "Develop their understanding of the history, heritage and culture of Scotland and gain an appreciation of local and national heritage within the world." and to "Broaden their understanding of past events, explore and evaluate different types of sources" and "Learn how to locate, explore and link periods, people and events in time and place". Under this curriculum, children in primary school do much of their information seeking activity during "topic work". Topics last 4-12 weeks, with $\sim 4$ dedicated hours per week. Mostly the work comprises classroombased structured activities carried in groups. The children in this study worked on a topic about everyday life in the Second World War (1939-45). Teachers designed activities about information seeking e.g. finding out about air raids. In most tasks, an artefact was produced and the task that we describe here was no exception. In this paper we investigate the behaviour that occurred during a poster-making task that occurred over 2 sessions of $2 \mathrm{~h}$ each. Children were used to participating in this type of activity and were aware of expected criteria for doing so. As well as creating the posters, an important criterion that the children knew they must meet in undertaking the task was that they should work well as a team.

During the project we identified a primary school and a class of 29 children aged 11-12, 1 teacher and one school head teacher. After a process of inquiry with stakeholders in the school, we identified a school activity to focus on, the Second World War: the home front. In the project we had the purpose of investigating how children search for and use information for school tasks with a view to designing tools tailored to this and used the time slot provided by this topic to do so. The process was articulated in four phases: class observations, group observations, focus groups and a teacher interview. In addition, children completed an evaluation form about the task which provided additional data about how they had experienced it. In this paper we will use the data collected from each of these phases to explore how children and teachers experienced a task around searching for information related to a historical concept, specifically, a wartime job, and creating a poster about it.

\subsection{Participants and setting}

We explored the stakeholders' attitudes and behaviours during the class observations, group observations, focus groups and teacher interviews. In the task discussed here we focused on children in their final year of primary school who are aged 11-12 years old. The topic work consists of activities that take place in blocks of $2 \mathrm{~h}$ twice per week over the course of many weeks with the task we report on here taking place over two consecutive sessions, during which the class and group observations were undertaken. In several subsequent sessions focus groups took place with one group at a time while the rest of the class were engaged with other tasks. In outlining the task each group was assigned a job e.g. Home Guard. Groups had to decide the role that each member would play: Reader, Recorder, Presenter or Designer. The teacher said they should include: title, information about the job, equipment used for the job, illustrations and that they should learn from each other. Children could use any of the classroom resources i.e. topic books, 2 PCs and another 4 PCs in a room nearby.

The task proceeded as follows:

1. Teacher outlined task to the children (whole class activity 30 mins)

2. Children searched for information and created posters (group activity $2.5 \mathrm{~h}$ )

3. Children from each group presented their posters to the rest of the class and the teacher (class activity 30 mins)

4. Focus groups with each group (group activity $1 \mathrm{~h}$ per group)

Within these sessions, 6 groups of 4-5 children produced a poster each. Two of these are pictured below along with an image of children undertaking their research (see Fig. 1).

\subsection{Data collection and analysis}

We used multiple methods: non-participatory observation during the class and group activities and then followed up with focus groups with the children and an interview with the class teacher.

Non-participatory observation: The class was observed in its interactions with the teacher at the start of each session. Following this initial class activity, one group ( 6 pupils) was closely observed as they made their poster but the researcher did not otherwise take part in the activity. The researcher had already established her role with the children. They could ask her questions but she took care not to be in a teaching role. The researcher then observed the whole class and made handwritten notes as each group made their presentations about their posters. The researcher gathered data about how the teacher outlined the activity, the children's behaviour and verbal contributions during the task, the detail of the posters created including the sources (e.g. book information, web information) and materials (e.g. printed images, hand-drawn pictures) used (see Fig. 2).

Focus group: 6 Audio-recorded focus groups were conducted in the weeks following the task, one group at a time. The posters produced, as well being a record of what they had found and which sources they had used, were used to get the children to evaluate their experiences of performing the task in order to uncover their preferences about how to search for interact with information. The researcher asked children to explain what they had included on the poster, pointing to specific elements of the poster to ask what each was about, why it was chosen, where it came from and how they had experienced the activity. Capturing experiences in the context of a co-design activity by having children draw has been shown to be effective $[12,13]$ and the use of props to conduct interviews with children was shown by [14]. The success of [14] came from children's pride in explaining what they created and pointing out what different parts of the drawing were. 

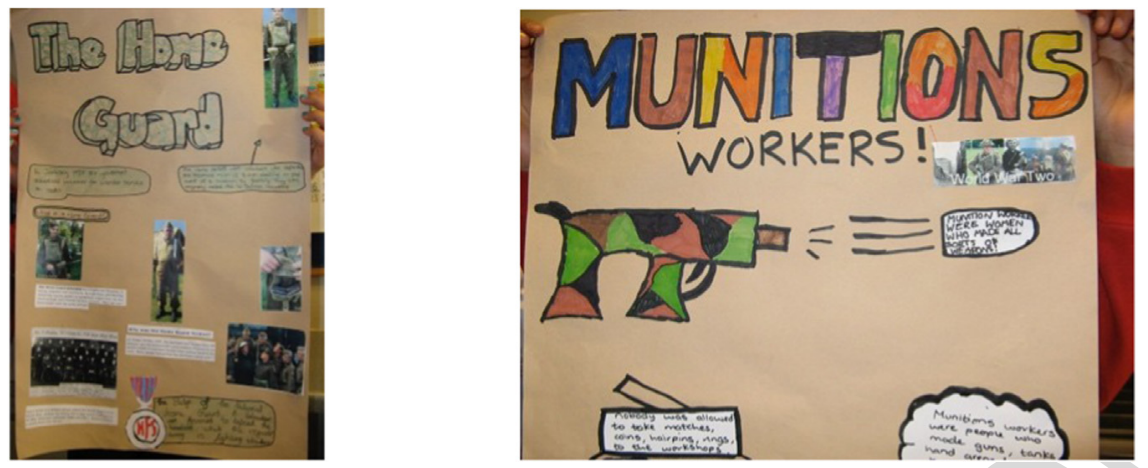

Fig. 1. Home Guard Poster, Munitions Poster.

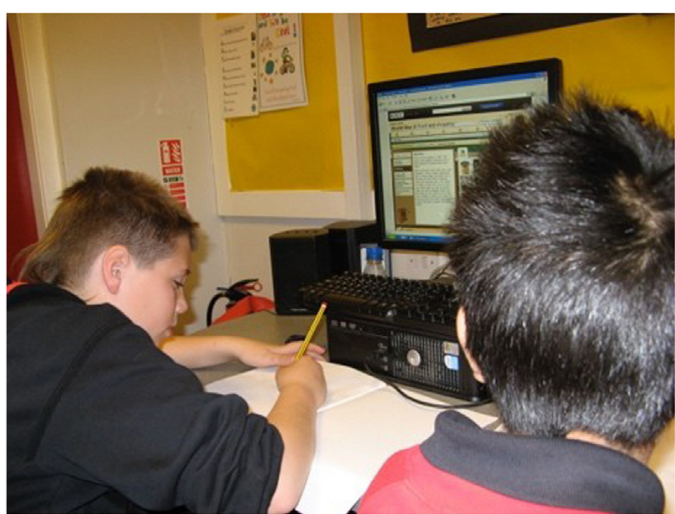

Fig. 2. Children searching online.

Teacher interview: The teacher was interviewed about how well she thought children met the criteria and about her observations about their engagement with the topic and their approach to carrying out the activity. An audio recording was made of the interview and handwritten notes were made by the researcher.

Data collected i.e. handwritten observation notes, transcriptions from the focus groups and teacher interview and the 6 posters produced were treated separately with coding and analysis done using a thematic approach. Transcribed data were coded inductively by identifying data patterns that were then associated with appropriate themes.

\section{Paper and digital resources in school (PADS)}

PADS aimed at designing technology to support teaching and learning in primary schools with a specific focus on the acquisition of reading and writing skills. During the project, two primary schools in the Italian speaking area of Switzerland were involved. The project lasted 5 years during which we engaged stakeholders according to the different phases. According to the schools' curriculum, children in primary school need to develop various linguistic competences (phonology, spelling, morph syntax, and lexicon) and to learn how to write various types of stories (fairy tale, fable, tale, myth and legend). Other important achievements are the development of social attitudes, creative thinking, digital literacy, self-esteem and self-evaluation skills. In particular, the development of a social attitude is extremely important at that age (6-11) thus the teachers often ask children to work in groups in order to stimulate them to interact with each other. After a process of inquiry with the schools' stakeholders we identified a specific school activity: literary genre and the writing laboratory. During the project two primary schools were involved, the Leonardo da
Vinci (LDV) and the Istituto Elvetico (IE), 130 pupils (aged 6-11), seven teachers and two school directors.

The purpose of this project was to design a new application to support children to create digital fairy tales in school during the time slot provided by "the literary genre and the writing laboratory". The co-design process was articulated in four phases: (1) activity analysis, (2) design and prototyping, (3) application evaluation, and (4) story evaluation. In this paper the data collected from the third phase will be used; when children produced the digital stories by directly using the developed application namely Fiabot! This phase includes all the elements needed for the description of the experience. "Fiabot!" is an iPad application that enables the creation of interactive and multimedia stories articulated in three main steps:

1. Definition of story structure and plot;

2. Media creation and editing;

3. Sharing within the class and publication of the story.

The stories produced are a mix of media (images, drawings, sound, music, dialogues, text) that represent the narrative.

\subsection{Participants and setting}

In the evaluation of the application the stakeholders' attitudes and behaviours during the writing laboratory were explored. Considering the project's goals, in this phase the focus was on 4th and 5 th grades, i.e. children aged 8-10. The writing laboratory is an activity that is held for two hours each week. This activity involved two teachers (one from each school) and 43 children (see Fig. 3).

Each evaluation session lasted for four days and was articulated in three stages (for more details see [15]):

1. Children's training, $1 \mathrm{~h}$,

2. Creation and sharing of the stories, $6 \mathrm{~h}$ each day for 4 days,

3. Focus group and contextual inquiry, $3 \mathrm{~h}$.

Within this evaluation session the children produced a total of 17 stories using Fiabot!. The outcomes of this phase have been exploited in different ways: feeding the re-design of the application, running a further study on how to design engaging digital storytelling for children, acquiring a better understanding of the role of technology in educational environments, and contributing to the improvement of methods for designing and evaluating with and for children.

\subsection{Data collection and analysis}

Multiple methods were used, in particular, during the sessions we collected data from a non-participatory observation, whereas 

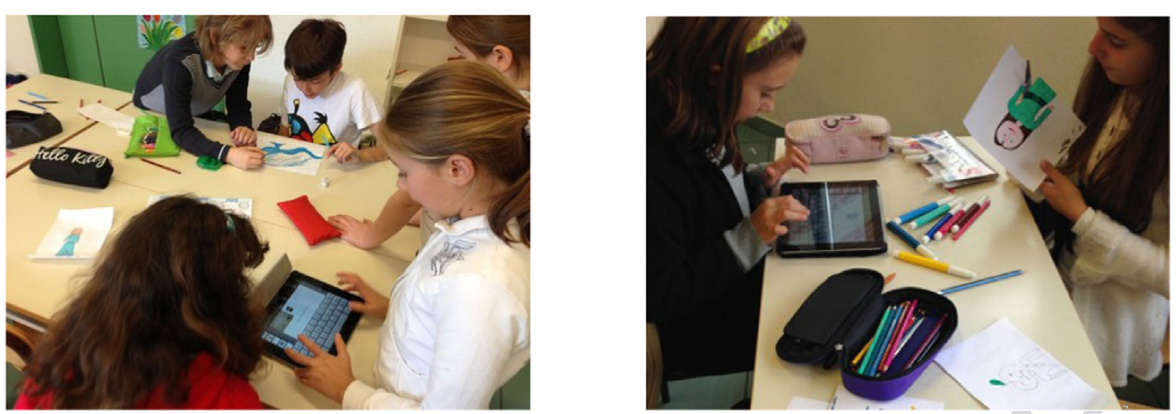

Fig. 3. Children create a story in class with Fiabot!.

Table 1

Study PD challenges and practical solutions.

\begin{tabular}{|c|c|c|c|c|c|}
\hline Project characteristics/PD challenges & Practical solutions PADS & \multicolumn{4}{|c|}{ Practical solutions CHIS } \\
\hline To fit into school timetable and settings & $\begin{array}{l}\text { PD activities to be designed together with } \\
\text { teachers. }\end{array}$ & \multicolumn{4}{|c|}{$\begin{array}{l}\text { PD activities following those tasks already designed by teachers and } \\
\text { head teachers to be congruent with demands of national curriculum. }\end{array}$} \\
\hline $\begin{array}{l}\text { PD methods to collect data accordingly to } \\
\text { the context }\end{array}$ & $\begin{array}{l}\text { Combination of qualitative data: } \\
\text { observation, interviews, focus groups }\end{array}$ & \multicolumn{4}{|c|}{$\begin{array}{l}\text { Combination of qualitative data: group and class observations, focus } \\
\text { groups, interviews, inspection of materials/artefacts produced e.g. } \\
\text { posters and an evaluation form }\end{array}$} \\
\hline $\begin{array}{l}\text { Technology available and in use at PD } \\
\text { process start }\end{array}$ & Access to technology regulated by teachers & \multicolumn{4}{|c|}{$\begin{array}{l}\text { Access to technology in classroom regulated by local authority and also } \\
\text { by the needs of other class groups in the case of technology resources } \\
\text { that were shared with the rest of the school. }\end{array}$} \\
\hline Group work & $\begin{array}{l}\text { Groups defined by teachers to ensure } \\
\text { smooth and productive collaboration }\end{array}$ & \multirow{2}{*}{\multicolumn{4}{|c|}{$\begin{array}{l}\text { Groups defined by teachers to ensure maximum participation and to } \\
\text { encompass a variety of skills, strengths and personalities } \\
\text { N/A }\end{array}$}} \\
\hline Stakeholders changing role during project & $\begin{array}{l}\text { Flexibility in PD procedure to enable } \\
\text { changes in roles and power shifts }\end{array}$ & & & & \\
\hline \multirow{5}{*}{\multicolumn{2}{|c|}{$\begin{array}{l}\text { following the evaluation session we ran contextual inquiry [16] } \\
\text { with the teachers and focus group with the children. } \\
\text { Non-participatory observation. At first, we participated in several } \\
\text { writing sessions and we studied the activities involved in the } \\
\text { creation of stories through repeated observations. We ran this } \\
\text { study in three classes for } 4 \text { sessions, totalling } 24 \text { h of activity. We }\end{array}$}} & & & & \\
\hline & & & $\begin{array}{l}\text { Primary } \\
\text { end-users }\end{array}$ & $\begin{array}{l}\text { Secondary } \\
\text { end-users }\end{array}$ & Other stakeholders \\
\hline & & ration & 130 pupils & 7 teachers & \\
\hline & & & 43 pupils & 4 teachers & 2 school directors \\
\hline & & groups & 43 pupils & 4 teachers & \\
\hline
\end{tabular}
phases (exploration, inspiration, production and sharing) of story creation using Fiabot!. Children worked in small groups of two to four members to create stories: through group work, children can also develop their social skills, which is an important pedagogical objective established in the curriculum. The researcher passively observed the activity and took notes. We gathered data on how teachers orchestrate the activity, the children's behaviour, the type of stories created and the materials used (i.e. pen, pencil, paper, etc.).

Contextual inquiry. We aimed at understanding the general and specific educational objectives, the task of the writing lab, the teachers' strategies, and the children's behaviour from their perspective. We interviewed two teachers separately and then we compared the data. The Contextual Inquiry was also driven at informing the data from the non-participatory observation.

Focus group. This had the purpose of investigating children's thoughts and attitudes regarding the experience they had as authors of digital storytelling using Fiabot!. The researcher acted as facilitator and, with the help of the teachers, ran the focus group. The findings were based on the children's self-perception of the story creation experience. We organised one focus group in each class (2) involving a total of 43 children.

Data collected were treated (transcribed, coded, and analysed) separately. Coding and analysis were conducted in the vein of thematic analysis, standing mid-way between an inductive and deductive coding approach. The transcribed data were initially coded in an inductive manner, identifying relevant data patterns that were then associated with themes. In a second wave, the relevant themes were grouped in relation to our main research questions [15]. The analysis was done to evidence the themes and associations between them.

Table 3

CHIS End-Users engaged in the PD Activities.

\begin{tabular}{lll}
\hline CHIS PD activity & Primary end-users & Secondary end-users \\
\hline Class observation & 29 Pupils & Teacher \\
Group observation & 6 pupils & \\
Creation of artefacts & 29 pupils (in 6 groups) & \\
Feedback form & 29 pupils & Teacher \\
Interview & & \\
\hline
\end{tabular}

\section{PD elements in the case studies}

Following, we summarise in Table 1 project characteristics and challenges together with solutions for both PADS and CHIS. In Tables 2 and 3, we describe for each PD activity the stakeholders involved in projects PADS and CHIS. These tables are inspired by work by Pilemalm [17]. They provide an overview of the two projects making it easier to spot similarities and differences among them.

\section{Conditions for participation: analysing the two case studies using the models' lens}

In what follows we present the data gathered in CHIS and PADS according to the five Conditions [9]: of Convergence, of Entry, of Social Support, for Competence, for Reflection. For each we provide a deep reflection on their implications for each case study. In particular, for the three elements Conditions of Social Support, Conditions for Competence, Conditions for Reflection, we articulate our reflections divided into teachers' and children's activities 
in order to have an overview of the different implications for the design process.

We will provide some quotations (in brackets) to exemplify the data that emerged from the study. As we did during the data collection and analysis we will use "T" and the associated number to identify the teacher for PADS while for CHIS only one teacher ran the activity in class. We will use the same strategy for identifying children's contributions with a "C" followed by an associated number.

\subsection{Conditions of convergence}

Both projects were developed with the full agreement of the schools, teachers, children and families. Indeed, both in PADS and CHIS researchers dedicated a huge amount of their time in creating the conditions in order to be sure the projects fitted with the actual curriculum in terms of content as well as of the schedule. In PADS this process took several months but it allowed a reciprocal understanding, and a trust relationship to be achieved. For CHIS we met with the teachers and head teachers several times in advance of the project to discuss issues of curriculum and to decide which areas of the curriculum and indeed which times in the school week would be most suited to being part of a study of this kind. In particular, in PADS we decided the topic to work on as well as the schedule together with the school. The project was based on children's and other school stakeholders' learning and teaching needs. The research project was fully shaped in accordance with this context. In the case of CHIS, making the convergence was perhaps more straightforward than for PADS as the intention was always to observe and evaluate those tasks that the class teacher had designed, carried out in the way that would be usual in the absence of a study taking place. For example, no researcher-designed searching tasks were employed in CHIS.

\subsection{Conditions of entry}

In our studies, we took a holistic perspective in order to understand the complex ecology of the school. In exploring the school as an institution, we integrated a hierarchical perspective with a curriculum viewpoint, so we looked at the organisational structure through a lens made of pedagogical objectives, practices, and contents. Integrating a curriculum-based perspective allowed us to explore the relationships between people working in the school, the economic and social aspects of the school, and the financial and structural resources. This approach provided us with a clear picture of the school, showing the elements that were fundamental in order to plan an intervention that aims to impact on children and teacher technology-related professional development.

For CHIS it was suggested by the head-teacher that the researcher spend a few weeks with classes of children at various levels in the school to get a better understanding of the school's character and ethos and the teachers' needs and style of working before making a decision about conducting more focused studies with one class initially (discussed here) and with another in a later part of the study. Families signed a consent form and were involved in a homework task later in the study (results not discussed here) and could see the output of the task, the posters, when they visited the school for a parents' evening. All of the CHIS research reported here took place in the usual classroom of the children or in an adjacent "open area" where students were used to using PCs and where there was space to conduct focus groups in relative quite without disrupting other class activities.

In PADS we decided which classes to involve in the project in accordance with the school stakeholders. We looked at teacher availability, the age of the children, and the suitability of the curriculum to the introduction of a technology. Families signed a consent form and at the end of the study were invited to an event in which children presented their stories. Children could always freely choose to participate or quit whenever they felt the wish to do so. The project was conducted at the school, in classrooms and in the laboratory, locations that were already booked by the teachers.

\subsection{Conditions of social support}

In both projects, children were treated with respect, much as they are used to in a normal school context. Both the teachers and the researchers always paid attention not to discriminate against those children who had more difficulties in using the iPad in PADS and the other tools and resources that were available in CHIS.

\subsubsection{Teacher's activity}

Both projects highlighted factors such as the ability to collaborate, share tasks and use technology as criteria for evaluation.

CHIS: Teachers, throughout the project, created groups using different strategies. For the task described here, teachers told us that they had picked groups for the task with a composition that they thought would maximise participation e.g. making sure each group had children with different skill strengths and interests. For example, they included those who were keen readers alongside those who were enthusiastic users of computers, and put those who had few serious conflicts with each together and avoided grouping children who had very strong friendships who thus might distract each other from focusing on the main task. When outlining the task at the beginning of the first session, the teacher asked the children to pick one of the roles she decided they should have in the group e.g. Reader, Recorder, Presenter, Designer with room for there to be more than one of these in each group. She also told them to learn from each other and stressed this again at the beginning of the second session of the task.

PADS: Teachers created groups to maximise productivity and to assure a constructive and friendly atmosphere for children to manage the tasks management and discuss the options. They made sure each group had a technology expert and let children free to look for and find solutions to technical issues as well as find strategies for decision-making. In addition, the teachers also created the groups in order to have different media literacy skills. In the evaluation of the stories teachers considered positively the ability of children to collaborate and create a nice co-working environment.

\subsubsection{Children's activity}

CHIS: children took responsibility for deciding on which of roles defined by the teacher that they would take within the group, deciding on search and selection strategies and distributing the undertaking of these to members of the group. Considering the well-defined task they also had to critically assess their achievement, both in terms of how well they thought it met the teacher's expectations but also on how well they thought they had done e.g. in terms of creativity and efficiency relative to other groups. From the focus groups it emerged that every child had been recognised by his or her peers to have contributed to the activity in some way whether it was in searching online, looking in books, or more obviously creative activities such as designing a title for the poster and there was sharing happening in terms of resources. Searching often happened in pairs, and children were responsible for making sure that they took turns to decide how to select and organise information for the posters, that each played his/her part in the poster creation and that no one person's ideas dominated too much.

PADS: children took responsibility for managing group work and assigning or distributing tasks. During the study we observed different situations: in one group a child became the leader and decided the turn taking regarding the use of the iPad as well 
as the distribution of work within the group, in others, children decided democratically or they fought for being the leader/doing the favourite task/using the iPad. However, despite some problems within the work group the final stories in the majority of cases were good. Indeed, just two stories were negatively affected by the group discussions. These were not completed and were evaluated by the teachers in a negative way.

\subsection{Conditions for competence}

\subsubsection{Teacher's activity}

Teachers helped children to express their views in different ways in the two projects, in PADS they provided explicit scaffolding via Fiabot!, in CHIS they left them free to set up their own methods and criteria to achieve the defined goal.

CHIS: The teacher introduced each session of the topic, defining the task and giving some sense of the steps to take and signposting the resources they might use but did not otherwise take an active part. She left children free to choose the preferred strategy to complete the task and to decide who in each group would be responsible for which aspect of the process. She did occasionally check on their progress and make sure they were still engaged on their task to meeting the objectives and success criteria she had defined for them.

PADS: Teachers defined the steps and the workflow in order to drive children to create the fairy tale. Thus Fiabot! supported children in the creation of the stories and helped them.

\subsubsection{Children's activity}

CHIS: Children acted as searchers, finding their own path by establishing search strategies and defining the workflow. They also played the role of judges in order to assess the quality of the search outcomes and deciding whether they could stop searching. All groups fulfilled the requirements: choosing roles, finding out about the topic, creating a poster. All 6 posters had titles, a rich variety of information found and selected from the available sources or illustrations about the topic as required, but they varied in how the children had chosen to add material to the poster, with some groups doing a lot of handwriting while others pasted printed text instead. Some groups made much use of photos where others relied more on drawings that were either copied or drawn from memory or imagination. A few groups had devoted much of their effort to creating a pretty title while others had used the time instead to post as much information as they could fit in the space. While there was some variation in quality, relevancy and quantity of information, all of the posters contained a rich variety of material.

PADS: Children acted as executors following the workflow dictated by the teachers and represented in Fiabot! in order to adhere to instructions. Within the group they defined who was in charge of the tasks using different strategies according to their skills and personality. The condition for completing the task was to have a completed story. They produced a total of 17 stories using Fiabot! The stories followed the structure of fairy tales and had a rich combination of media: images, audio, text and video.

\subsection{Conditions for reflection}

Both CHIS and PADS had reflective moments when children, teachers and researchers came together and discussed their expectations and motivations at different stages of the project. Initially teachers explained what the outcome of the task was going to be, how it would be assessed, and their expectations in term of group work. Finally, the children met with researchers in focus groups to discuss critically the overall experience of the tasks, which provided opportunities to evaluate both group and individual efforts and to reflect on future directions for the study.

\subsubsection{Teacher's activity}

In CHIS, the teachers acted as facilitators by defining the overall task that the children should do but had a lesser role supporting them while performing the task than was perhaps the case for PADS. The support given was mostly in the form of occasionally observing each group as they carried out their searching and poster making to check that children continued to engage with the task and to ensure that distractions and conflicts were kept to a minimum. In doing this the teacher was also lightly monitoring the process of the task, getting a feel for how children were understanding the educational objectives of what they had been asked to do and observing how they negotiated turn taking, team working, resource sharing, decision making. During the presentations the teacher was also able to get a sense of how well the children individually and in their groups had contributed to and learned from the task. The teacher assessed the posters created based on overall design, quality, variety and relevance of the information included and during the group presentations of the posters she assessed each group on how well they showed understanding of the wartime job they had been given to research. According to the teacher's evaluation, all of the groups had understood the task well and completed it in a reasonable way, making mostly good use of the resources provided though she had been disappointed by the quality of several of the posters and in how well they had learned and understood information about the topic. In the following we report the main elements that emerged from the study.

The task as designed had encouraged organisation of the work within a group to an extent but this had not always been successful despite group working being part of the ethos of the class. "Some (worked in groups) better than others. Group work is something that this school places emphasis on to prepare children for high school ... and so since last year there has been a particular emphasis placed on it."

Collaboration as inspired by the activity, had not always been enough to overcome the difficulties the children had with the task: "It's how they take that information and make it their own-I think that's what they are finding difficult. It varies across class-some kids have much lower reading level than others but it's about trying to get everyone to access the info in some way, which is the idea behind group working, and the idea of teacher support. Pinpointing those who struggle and pushing those who are doing well."

Taking part in the task had stimulated autonomy of the children as it allowed, for example those who enjoyed the technology aspect of the task for example to focus on that but it did not necessarily lead to better task outcomes: "They love using the computers. I think they are possibly more enthusiastic when it is their turn to use the computer... However, they find it difficult to search for exactly what they are looking for. I think they absolutely adore using the internetit's the most exciting thing for them. They love it. I also think for the kids who are poor readers the Internet, being technology and having pictures etc., that has probably met their learning needs better. (however)... I feel the books have helped more.... I think they understood the books very well because the level was right and appropriate for them and we don't have the same control over what they can use on the internet. That's why I think they got more out of using the books."

Carrying out the task had not fully led to the achievement of pedagogical objectives: not all of the posters produced were of high quality. "I was slightly disappointed with some of them because I felt that they hadn't understood the information that they had written on there. Not the case for everyone but some had copied screeds, which they had been told not to do".

Taking part in the task had not led to full compliance with pedagogical objectives with the teacher reporting that not all of the groups had fully met the success criteria indicating a need for better support: "They should (have been aware of the success criteria) because this is how we begin all of our lessons ... they didn't quite meet 
the criteria. Some did, some didn't." "the level of the information was too difficult for them, they found it very difficult to make sense of the information on the internet...(Some children) did get there in the end with it but certainly for some kids they have just copied screeds from a website (and I know which website it is)."

In PADS teachers acted as facilitators, by defining the main task that should be performed by the children, and supporting them in performing in class. The way they supported the children changed according to the specific pedagogical benefits that they aimed to achieve. As mentioned above, the primary school curriculum includes many educational objectives specifically related to the topic (i.e. literary genre) as well as to the development of other personal abilities (i.e. social skills). Children have to learn how human and social organisation works. Thus, starting from the first grade, teachers organise class activities to include group work. In these activities teachers provided a positive evaluation when the children demonstrated the ability to distribute the tasks among themselves with the purpose of successfully achieving the educational objectives and involved all the members of the group. The mark is negative when children do not interact within the group, or when one or more were not engaged in the activity. In order to achieve this objective, teachers created groups using different strategies. If they aimed at favouring the achievement of social skills they might create groups in which more than one child has a temperament for leading: the possible scenario in this case is that children might fight for to lead the group and the story would suffer from this discussion. On the other hand, teachers create groups in which the personalities of children are well balanced in the direction of favouring good group work and the story that is created benefits from stable group work. In the third phase of the PADS project teachers decided on the second strategy: children were grouped in small teams of up to four members each. The teachers assigned children to groups using their deep knowledge of the children's skills, attitudes, and personalities so that the groups would have comparable strengths and abilities. Each team was built to have a good balance in terms of specific pupils' abilities, covering: digital literacy, social skills, creativity, and knowledge of the curriculum topic. The role of the teachers was fundamental to defining the mood of the group work and this affected the final result. However, the quality of the story was not yet ensured. Indeed, even if the groups were well-balanced, children still in some cases experienced difficulties with turn taking as well as in sharing their ideas and handling the tasks.

Overall, the teachers evaluated the improvement of the children's competence by analysing each story from different perspectives: the narrative quality was assessed by the teacher in terms of originality, media literacy, ability of collaborating within the group, and adherence to literary genre (in this case a fairy tale). All of these aspects are considered relevant for the fulfilment of the curriculum objectives. According with the teachers' evaluation $90 \%$ of the stories were valued with a high score, between 4.5 and 5 . Teachers rewarded the groups that collaborated well. Teachers reported that Fiabot! encouraged the organisation of work within a group. T1: "I have noticed that the workflow of Fiabot! imposed on the children to discuss about how to distribute the work within the group. Especially the first module-definition of story structure and plot-helped them to reflect on the type of story they wanted to create. They listed the tasks and then distributed the work according to the abilities of each member."

The teachers noticed ways in which the technologies proposed stimulated the collaboration among the group members, and activated a scaffolding process among the peers. T3: “... pupils have improved in their ability to listen to and understand each other, they are able to put ideas together and work on a common story script. Previously they were all working in isolation now they really are a group! They get to know with whom they could work productively."
T2: "Fiabot! stimulated group discussion on the plot of the story and allowed a reflection of pupils on their abilities and skills. Children demonstrated a great maturity in focusing on the final objective and sometimes in overcoming personal wishes. In some cases, one member led the distribution of tasks."

Technology engaged teachers and pupils in activities that improved their autonomy. Pupils had an active role by proposing some activities to the teachers and motivating them in using it. Indeed, in some cases they had sufficient self-confidence to become the leaders of the activity. As reported by T3: “...I never had to use any of the tools provided by the researchers, the children did everything by themselves". This extract shows very clearly how teachers could be passive in their involvement with technology as children take a leading role. A perfect description of the role of a Follower where the focus is on the educational task of letting children take responsibility for their learning. T3 added: "...my pupils would also like to write their exams using their $\operatorname{PPad}^{T M} s$, they asked for that explicitly. All pupils in my class have an iPad ${ }^{T M}$ at home. They feel so confident about using it that they offered to help one of their classmate's father who is involved in a project for the creation of stories." Again, another sign of teachers giving space to children to take initiative and behave independently when using technology. T3 explained: “...my pupils are able to self-assess. They are equally able to understand how much they can accomplish and assess their peers too. This is a great improvement; all my pupils are good at selfassessment."

In order to understand the real achievement of pedagogical objectives it is important to consider the teachers' assessment of the story in relation to the criteria used for marking such as creativity, media literacy and their ability to create narratives consistent with the fairy tale genre.

According to the teachers' marking, $60 \%$ of the stories obtained a very high score. Children demonstrated themselves as being original and creative. T1 'In 'Luke and the savior' story. Children took inspiration from Hunger Games but they didn't copy the game. They used the strategies of the game in the story by creating complex narrative mechanisms that were very intriguing for the audience...there was an improvement in the level of discussion and engagement of pupils in creating the character of the story and the plot." T2 "I really liked how in the plot 'Virginia the vain' children integrated some episodes from one child's family with other elements that were invented."

Regarding the use of media, $67 \%$ of the stories were marked with a score between 4 and 5 . They enjoyed creatively mixing digital media such as audio, images, and videos, and text within the story.

T1. "The opportunity offered by Fiabot! for creating, editing, and importing different media allowed the children to understand the different features of each of the contents. In addition, looking at the stories, it is evident how children explored the different languages in order to understand which was more suitable and added value to the story".

T2 "In 'Everything happened in one night' children created a blues ballad to describe the main characters of the story. In addition, the associated images of the characters gave a great added value to the audio and text... The options offered by Fiabot! in module 2 really encouraged children to use different types of media."

Looking at the compliance with the fairy tale narrative genre, $70.5 \%$ of the stories received a score higher than 4 . The children learnt the structure and ingredients of the stories as well as the rules for creating a specific narrative typology. T1 "I can see the benefit of using Fiabot! from the way they built the plot of the stories. They created correct narratives but they used the elements of the story in a creative and unusual way. For instance, the protagonist of one of the stories is the crown, not a person, but a magic object! This choice is quite original and correct at the same time."

T2 "I can affirm that Fiabot! helped children to consolidate their knowledge in this genre. For instance, when they had to conceive the ingredients in module 1 they discussed a lot about the possible characters and the plot...during the discussion they used the appropriate language to indicate the characters and other elements of the story." 


\subsubsection{Children's activity}

CHIS. In an evaluation sheet given out by the teacher and completed immediately after the task (before the presentation and focus groups took place) children showed high self-esteem by rating their task performance highly, somewhat in contrast with how the teacher had viewed their performance. In fact the group that the teacher thought had performed worst on the task, all said they thought they had done very well. In the focus groups, all groups were a bit less sure about how well they had done, particularly once they had a chance to see the other posters and could make a comparison. At this point they became assessors not just of their own work but also of the work of others. Seeing the efforts of the other groups caused a few groups to reflect that they could have made more effort and included more or better material. During the focus groups the reasons why they had chosen each piece of information for their posters and which pieces of information they thought were most useful for the task emerged in the discussions. On a couple of occasions this led to children realising they either had not fully understood the information they had included or even that the information related to another wartime job entirely from the one they had been asked to research. So while their self-esteem went down a little following this reflection, in general children said that they had liked the experience of creating the posters. Some said they enjoyed the group work aspect, some liked having the chance to do some artwork by drawing some parts of the poster. In fact the emphasis and effort that a few groups had placed on the design of the title of the poster for example was greatly at odds with the importance that the teacher placed on this. In line with this, the children's assumption about which poster was the best was at odds with that of the teacher who perceived it to be the least well conceived. Children had chosen the best poster based on its layout, title design and colours where the teacher knew it contained factual errors and irrelevant information and thus rated it poorly.

Some of the children made a point of saying they liked using the technology for the task with some children mentioning enjoying multiple parts of the activity. "It was quite fun cos I got so many different jobs to do. I had to take notes I had to research with the others and I had to draw the poster with someone else" C1. "It was enjoyable - I like going on the computer with a partner and I like finding out new stuff" C2. "I liked it because we didn't do what we do normally. We did it as a group on computers not just with information the teacher gave us and we did it on our own and I am proud of what we did" $\mathrm{C} 3$.

Children clearly felt they were playing a role in decision making about how the task should be conducted.

"We decided to do it another way so it would not be copying - it would be in our words and it would be better" C4. They felt taking part in the task had led to increased competence, "I think we did quite a good job and we found quite a lot of 'brand new' information on the internet. It was new to us and we could learn from it" C5. Taking part had given them the means to go further with their research in their own time on areas of their own initiation: "When I was doing research at home about this I found out that gas masks could be bad for your health" $\mathrm{C} 6$. Additionally, the exercise led to a sense of responsibility and influence about their use of the information. "Was good to put this info on in case there is a war again". "I think the drawings and pictures were good but we could have used some more to let people know more about what life was like" C7.

So it seems that children were investigating the topic outside of school time and that even the children with lower ability were getting something from the task, increasing their agency. The teacher said: "Some kids have obviously got some additional info possibly from internet, or books or possibly from research done in own time. For those who usually do well we are getting a high standard of work from them on this topic as usual. Was surprised by the work that some of the lower ability groups managed to do".
PADS. During the focus group children commented on their experience by highlighting how this experience supported them in acquiring new competences and their self-esteem increased a lot: "Me and my classmate created a whole multimedia story as professionals" C15. "I have shown my dad the multimedia story and the audio that I have created like a director" C20. "I told my mother that now I can help her and write with the computer and editing images" C18. ".... and now I am a storyteller and I can create engaging stories" C22.

In addition, the teachers reported on how the level of agency was also improved. T1: "Overall, children are more active in the creation of the story using Fiabot! than using other canonical artefacts. In particular, the way Fiabot! gave the children the opportunity of being authors of something original and unique that could be shown to their friends and family". T2: "Stories in general were very rich and well done. Thus, pupils were satisfied of [sic] their work and felt [themselves] to be author[s] of multimedia contents. This helped me a lot to reinforce their self-esteem which is a fundamental element to which the elementary school is addressed."

\section{Conclusions}

We have described and compared two projects: PADS and CHIS, both involving children of similar age in the design of new technology in a school context. For both we have analysed the conditions for participation as described in Ivari and Kinnula [9] and kept children and teachers' activities separated in order to find an answer to our initial research question: what are the conditions that impact on children's level of participation, as well as on the roles that pupils play within the co-design process?

Overall, from our comparison it appeared that the educational goals set by the teachers have a direct influence on children's performance and the roles they take in the design process as mentioned in the reflections upon both design experiences. By explicitly keeping a distinction between activities performed by teachers and children we could observe a strong dependence between the procedures set by teachers for children, and the performance and achieved level of competence of the children.

Two main aspects have emerged worth further investigation.

Under Conditions for Competence: the decisions taken by teachers made a difference in terms of the roles children played, the degree of freedom and independence they took in performing the assigned tasks and the quality and originality of their productions. It was noticeable how in CHIS pupils were both executors, managers of group resources and subtasks necessary to lead to task completion as well as judges of the quality of their work. In PADS they were mostly executors, by following the workflow decided by the teachers and replicated in Fiabot!, group-work managers, defining the roles and the tasks within the process, and media creators, for the multimedia story. Looking at the artefacts produced within the two process we can see some consistent differences: in CHIS these had a great variety and expressed the free spirit of their authors, while in PADS all stories adhered to the required structured but differed in terms of the plot, the originality and percentage of multimedia material. Given the nature of the two projects these products represent quite well the structure of the task and the process of creation.

Under Conditions for Reflections; children engaged with CHIS were left free to decide how to run the required task. They were urged to take on the role of assessors and adopted criteria opposite to those of their teachers, showing how they had a very different understanding of the motivations and quality issues involved. Overall even if their posters were not of as high a standard as teachers expected, they had further developed their ability to critically discuss, reason and reflect on their work and that was the main positive outcome of the design process. This confirms 
the need for better defining criteria and purposes behind tasks in proportion with the degree of freedom given to children involved and the roles they are asked to play. In PADS children acquired new skills, competence and confidence by deeply engaging with stories writing by following a workflow that drove them through the process of creation. During the design phase they played the role of informants and designers with the researchers. However, in the evaluation phase, when they used Fiabot! they mostly executed tasks as instructed to by their teachers.

Teachers are experts in setting suitable educational goals in order to engage and motivate children in the learning experience. This expertise surely helps in devising activities to similarly engage and motivate children during design activities at school as very often teachers' and researchers' goals tend to overlap and ideally converge [9]. In our study we emphasised how adherence to curriculum is important for motivation and participation as much as a deep understanding of educational intentions defines the way children will engage with the activity and the roles they will be able to take on. Thus, we suggest a more thorough analysis of educational goals to cover not only the learning outcomes of the activity but also the expected competences the process will generate. A full convergence will be conducive to more engaging design experiences.

\section{Discussion}

We began the paper by discussing Druin's work [1] on the roles that children can take in design, considering this model of children's roles in co-design and believe that in our investigations we have been successful in highlighting the role that children took in the different phases of each project in respect to the teachers' attitude about the roles they should or indeed could take at that point in the activity. By studying both projects in parallel we discovered that children can play the same role in different ways according to the specific context of how a task is executed. For instance, when children were in the role of informant in CHIS project they did so while engaging with the tasks set by their teachers and then took on the active role of evaluators of their own performance of the task as they discussed their posters. In contrast, in PADS the children were in the role of informants when engaged in the evaluation of the tool under design. Taking the notion of children's roles in design further we feel it is also worth mentioning Iversen et al. [3] in this regard. Their description of child as protagonist in the design process whereby they are empowered to change the objective process of design and outcome measures of that design process is of relevance here but to different degrees in each project. Iversen et al. argue that alongside the roles defined by Druin children can also act as protagonists in the design process if researchers (or others) encourage them to be the main agents driving the design and that they also encourage them to develop design skills and reflect on the role of the developed technology in their lives. In both projects we feel we saw children enabled to take on this role of protagonist to varying degrees.

In CHIS children had the opportunity to reflect in the focus groups not just about the experience of carrying out the task and how well they had done this but also on how useful the different types of resource had been including the value and difficulty of using the technological resources versus the paper and other book based resources. It was only in the focus groups that they had the chance to really see how correct the technology resources had been and to express their frustrations at not being able to always find what they needed, and also to discuss with others why that might have been the case. In PADS children were engaged in reflection about the design of the Fiabot! application in all the stages of the design process. Children were engaged through focus groups and user test evaluation. During the design process they expressed their satisfaction in being part of a research project, and their awareness on their role as informants when we ran the first FG to elicit the user requirements, and then again during the evaluation session. In fact, the name Fiabot! was chosen by them during the first FG and they referred to this application always as "our app". Another important aspect concerned the change of perception regarding the use of technology. After a few months of children being engaged in the stage of analysis and design, there clearly emerged a change of perception. Parents reported to teachers that their children valued the iPad they had at home as an artefact that could support them for learning purposes instead of as merely a tool for playing as was the case before the study.

Our data from CHIS and PADS suggested that using this lens in engaging children has several benefits in terms of gathering better research results, making a deeper design issues analysis and support the children design skills development.

\section{Limitations and future work}

One limitation of this work is that we focused on a relatively small group of users and would argue that extension to a wider sample would improve and reinforce our results. In addition, the lack of a proper framework to help us plan our study and make sense of its findings is surely a more serious drawback. Nonetheless, we feel that keeping children's and teachers' activities separated in the analysis of conditions for participation, helped us to discover the dependencies between these and to better understand the importance of educational goals at large on the levels of participation and possibly engagement and motivation of children in design activities. This, in turns suggests the direction to take when devising a new framework to combine and extend existing ones in order to support researchers planning and evaluating design experience in school context.

\section{Uncited references}

[18], [19], [20], [21], [22], [23], [24], [25], [26], [27], [28], [29], [30], [31]

\section{References}

[1] Allison Druin, Cooperative inquiry: developing new technologies for children with children, in: Proceedings of the SIGCHI Conference on Human Factors in Computing Systems, ACM, 1999.

[2] Mona Leigh Guha, Allison Druin, Jerry Alan Fails, Cooperative inquiry revisited: Reflections of the past and guidelines for the future of intergenerational codesign, Int. J. Child-Comput Interaction 1 (1) (2013) 14-23.

[3] Ole Sejer Iversen, Rachel Charlotte Smith, Christian Dindler, Child as protagonist: Expanding the Role of Children in Participatory Design, in: Proceedings of the 2017 Conference on Interaction Design and Children, IDC '17, ACM, New York, NY, USA, 2017, pp. 27-37.

[4] K. Summers, K. Knudtzon, H. Weeks, N. Kaplan, Y. Chisik, R. Kulkarni, S. Moulthrop, Contextual inquiry into children's reading: Working with children as research partners, in: Proceedings of the UPA Conference, June 2003.

[5] Janet C. Read, Daniel Fitton, Matthew Horton, Giving ideas an equal chance: inclusion and representation in participatory design with children, in: Proceedings of the 2014 Conference on Interaction Design and Children, ACM, 2014.

[6] Judith Good, Judy Robertson, CARSS: A framework for learner-centred design with children, Int. J. Artificial Intel. Educ. 16 (4) (2006) 381-413.

[7] Gabriella Dodero, et al., Towards tangible gamified co-design at school: two studies in primary schools, in: Proceedings of the First ACM SIGCHI Annual Symposium on Computer-Human Interaction in Play, ACM, 2014

[8] E. Mazzone, N. Iivari, R. Tikkanen, J. Read, R. Beale, Considering context, content, management, and engagement in design activities with children, in: Proc. IDC, 2010, pp. 108-117.

[9] Netta Ivari, Marianne Kinnula, Inclusive or inflexible: a critical analysis of the school context in supporting children's genuine participation, in: NordiCH '16: Proceedings of the 9th Nordic Conference on Human-Computer Interaction, 2016. 
[10] L. Chawla, H. Heft, Children's competence and the ecology of communities: A functional approach to the evaluation of participation, J. Environ. Psychol. 22 (2002) 201-216.

[11] A. Engle Randi, Faith R. Conant, Guiding principles for fostering productive disciplinary engagement: Explaining an emergent argument in a community of learners classroom, Cognition Instruction 20 (4) (2002) 399-483.

[12] Emma Nicol, Eva Hornecker, Using children's drawings to elicit feedback on interactive museum prototypes, in: Proceedings of the 11th International Conference on Interaction Design and Children, ACM, 2012.

[13] C. Sylla, P. Branco, C. Coutinho, M.E. Coquet, Storytelling through drawings: Evaluating tangible interfaces for children, in: CHI 09, ACM, 2009.

[14] Emma Nicol, Using artefacts to investigate children's information seeking experiences, in: Proceedings of the 5th Information Interaction in Context Symposium, ACM, 2014

[15] Elisa Rubegni, Monica Landoni, Fiabot!: design and evaluation of a mobile storytelling application for schools, in: Proceedings of the 2014 Conference on Interaction Design and Children, IDC '14, ACM, New York, NY, USA, 2014, pp. 165-174.

[16] Karen Holtzblatt, Sandra Jones, Contextual inquiry: A participatory technique for system design, in: Participatory Design: Principles and Practices, 1993, pp. 177-210.

[17] S. Pilemalm, Participatory design in emerging civic engagement initiatives in the new public sector: Applying PD concepts in resource-scarce organizations, ACM Trans. Comput.-Hum. Interact 25 (26) (2018) 1-26. http://dx.doi.org/10. $1145 / 315242$.

[18] Mihaly Csikszentmihalyi, Finding Flow: The Psychology of Engagement with Everyday Life, Basic Books, 1997.

[19] Gabriella Dodero, et al., Towards tangible gamified co-design at school: two studies in primary schools, in: Proceedings of the First ACM SIGCHI Annual Symposium on Computer-Human Interaction in Play, ACM, 2014

[20] Stephanie Houde, Charles Hill, What do prototypes prototype, in: HandBook of Human-Computer Interaction, vol. 2, 1997, pp. 367-381.
[21] Hilary Hutchinson, et al., Technology probes: inspiring design for and with families, in: Proceedings of the SIGCHI Conference on Human Factors in Computing Systems, ACM, 2003.

[22] Joan Greenbaum, Morten Kyng (Eds.), Design At Work: Cooperative Design of Computer Systems, L. Erlbaum Assoc. Inc., Hillsdale, NJ, USA, 1992.

[23] Ole Sejer Iversen, Christian Dindler, Sustaining participatory design initiatives, CoDesign 10 (3-4) (2014) 153-170.

[24] Lewis Theodore, Stephen Petrina, Annie Marie Hill, Problem posing-Adding a creative increment to technological problem solving, 1998.

[25] Elisa Rubegni, Monica Landoni, The TRiTS model: teacher roles in introducing digital technology into a school curriculum, Cogn. Techno. Work 18 (2) (2016) 237-248.

[26] Elisa Rubegni, Monica Landoni, Evaluating engagement in reading: Comparing children and adult assessors, in: Proceedings of the 15th International Conference on Interaction Design and Children, ACM, 2016.

[27] Elisa Rubegni, Monica Landoni, Supporting creativity in designing story authoring tools, in: Proceedings of the 14th International Conference on Interaction Design and Children, IDC '15, ACM, New York, NY, USA, 2015, pp. 287-290.

[28] Elisa Rubegni, Paolo Paolini, Comparing canonical and digital-based narrative activities in a formal educational setting, in: Proceedings of the 9th International Conference on Interaction Design and Children, IDC '10, ACM, New York, NY, USA, 2010, pp. 258-261.

[29] Elizabeth B.-N. Sanders, Pieter Jan Stappers, Co-creation and the new landscapes of design, Co-Design 4 (1) (2008) 5-18.

[30] Cristina Sylla, et al., Storytelling through drawings: evaluating tangible interfaces for children, in: CHI'09 Extended Abstracts on Human Factors in Computing Systems, ACM, 2009.

[31] Diana Xu, Janet C. Read, Gavin Sim, Barbara McManus, Experience it, draw it, rate it: capture children's experiences with their drawings, in: Proceedings of the 8th International Conference on Interaction Design and Children, ACM, 2009, pp. 266-270. 